\title{
Technical Communication in the United Kingdom: The Academic and Professional Contexts
}

\author{
Yvonne Cleary \\ University of Limerick \\ yvonne.cleary@ul.ie
}

\author{
Marie McCullagh \\ University of Portsmouth \\ marie.mccullagh@port.ac.uk
}

\begin{abstract}
Although technical communication is an active field of work in the United Kingdom, currently no academic programs are offered in this discipline. Interviews with practitioners, a company owner, and members of the board of the Institute for Scientific and Technical Communicators explore technical communication in the UK, specifically focusing on education and training, professional associations and communities, professional practice, and the future of the discipline. Findings reveal that, without an academic foundation, the profession is relatively unknown and practitioners have qualifications in other, sometimes unrelated, disciplines. While the current labor market is positive, interviewees are uncertain about future developments.
\end{abstract}

Index Terms - United Kingdom, academic, professional, interviews, technical communication.

\section{INTRODUCTION}

In traditional professions (e.g. law and engineering), professional schooling and professional associations work in tandem to circumscribe professional skills, career paths, status, and market closure [1], [2]. Recognized academic programs ensure a fixed path into the profession, and a relative monopoly for those who have acquired the requisite academic qualification. Professional associations may accredit academic degrees, to demonstrate the quality of the educational offering. These associations offer additional supports for practice, including publications and advocacy services.

Although technical communication is a relatively new profession, in many countries academic programs and professional associations in this field support education and initiation into practice in traditional ways, and there is a solid academic and professional basis for practitioners (e.g. in the United States, Canada, and Germany). In Europe, the TecCOMFrame project was established to address the lack of academic programs in technical communication in many countries (see [3] for a description of that project). In the United Kingdom (UK), no full academic program in technical communication is offered, although programs at master's level did run in the 1990s and 2000s.

This paper describes an exploratory study that begins to address a dearth of recent research by examining the academic and professional contexts for technical communication in the UK. The study described in this paper involved interviews with technical authors, a professional society representative, and a service and recruitment company representative. Secondary sources, including academic, recruitment, and professional society websites, also informed the findings. The focus of the study is technical communication in industry.

Many factors make this study timely, and the UK a compelling site for examination, including how technical communication emerged as a professional field, and its educational landscape. The tension between traditional and changing roles due to technology developments, synergies with other roles, and the impact of political developments are additional contemporary factors likely to affect interviewees' views of education and training in technical communication in the UK.

This paper begins with a literature review that discusses relevant research about the professional and educational context, and communities in technical communication. The literature review enabled us to identify a set of research questions that we set out to explore through interviews, described in the Methodology section. We then present preliminary findings, draw conclusions, and identify areas for further research.

\section{LITERATURE REVIEW}

While technical communication developed worldwide in response to the need to provide instructions for complex products, the professional context, educational opportunities, and support communities have evolved in different ways depending on local cultures, economies and labor markets. 


\section{Professional context}

In the UK, technical communication has historical roots in the manufacturing, engineering, and science sectors. The field developed in response to a strong manufacturing economy, and the need for instructions for complex products. Until the 1970 s, engineers with no specialized training in technical communication wrote technical documentation to support aviation and engineering products and procedures [4]. They took vocational training programs to improve their writing and design skills, initially training outside of the university system [4], [5].

While no recent studies have explored current technical communication roles and job titles in the UK, the IT JobsWatch recruitment site [6] indicates that, like in other countries (see [7], for example), job titles are becoming more varied. For example, job vacancies for 'technical authors', have been falling since 2005, while vacancies for 'technical writers' are relatively static in that period, and vacancies for various 'content' roles (e.g. developers, editors, designers, strategists, and coordinators) are all increasing. Notably, 'content manager' and 'content management' are both falling, following a peak between 2010 and 2014.

The UK is one of only two countries in the European Union where English is the first language. This distinction, together with a strong economy, ensures that employment prospects are strong in the manufacturing and technology sectors (see [8] for a discussion of graduate prospects in these sectors in the UK). The impending exit from the EU, however, may have an impact both on the economy and on the types of industries that are strongest in the future.

No recent research is available on the professional context in the UK, or the types of work undertaken. Without a clearer understanding of the current labor market, it is impossible to develop programs that prepare students for contemporary workplaces.

\section{Educational context}

Certified academic qualifications are considered strategically important to a profession, because they help to delineate the skillset, increase the quality of the work, and ensure that only qualified individuals can practice in the profession [1], [2]. Gorman and Sandefur [9, p. 277] have argued that education distinguishes professional from non-specialized, work: "As economic inequality grows in developed nations, the important line of demarcation increasingly lies between jobs and occupations that require expert knowledge - in the form of specialized higher education-and those that do not" (p. 277). Although successful technical communication programs were offered in universities in the UK in the 1990s and 2000s, at present no full undergraduate or postgraduate program is available [10]. The University of Reading offers an MA program in Communication Design which includes some content relevant to technical communication and the University of Portsmouth offers a module on technical communication as an option on its MA in Translation Studies. A similar module is also offered as an option to undergraduate final year English language and Applied Language students.

\section{Communities}

In technical communication, as in other work areas, communities support professionals in their education, professional development, and practice. Communities may be formal, such as professional associations, or informal, such as communities of practice [11].

Several professional associations support technical communication practice, including the Society for Technical Communication (STC), tekom Europe, and the Institute for Scientific and Technical Communicators (ISTC).

According to its website [10], the ISTC is "the largest UK body representing information development professionals." It was founded in 1972, through the amalgamation of preexisting organizations. The ISTC offers several supports to members, including an annual conference, a trade publication and newsletters, discussion forums, events, and local area groups.

No recent research has explored the role, activities, or impact of the ISTC for practitioners in the UK. Additionally, no research has examined other types of professional communities, including online communities, in technical communication in the UK.

\section{METHODOLOGY}

The purpose of this study is to increase understanding of technical communication in the United Kingdom.

\section{Research Questions}

We began with a broad objective, to explore the educational, training, and professional landscape, and to determine whether and in what ways the lack of educational offerings affects practitioners, specifically, and the profession in the United Kingdom more generally. From this broad objective, we distilled three research questions:

1. How do practitioners characterize their professional contexts?

2. To what extent does the lack of educational programs in the UK impact on the profession?

3. To what extent are UK practitioners involved in professional communities?

\section{Interviews}

To respond to the research questions, we planned interviews with four practitioners, who included among their number a company owner, and members of the ISTC board. The interviews were semi-structured. While we prepared specific questions, we were also willing to deviate from the questionnaire to explore relevant tangential 
discussions with individual interviewees. Each interview lasted for approximately one hour. All interviews took place in November and December of 2019. During this period, British EU-exit (Brexit) negotiations were ongoing and the political situation was one we discussed with interviewees, considering the potential impact of political and economic instability on the technical communication labor market.

We developed an interview schedule and a list of indicative, mainly open-ended questions, that covered the following topics:

- Career history.

- Education: individual background, training, views on offerings in the UK.

- The profession in the UK.

- Communities of practice and professional associations.

- Future projections.

\section{Data analysis}

We recorded and transcribed each interview. Following initial reading of the transcripts, we used Excel to code for specific patterns. We identified excerpts from the data that corresponded to themes and categories in our research questions. At this stage in the study, our data collection and analyses are preliminary.

\section{RESULTS}

All of the interviewees had worked in the software industry and their knowledge and expertise had been primarily developed in this area. There was considerable variation in job titles and also in the amount of time they had been in industry, ranging from over 25 to less than 5 years (see Table 1).

TABLE 1. INTERVIEWEE SUMMARY DATA.

\begin{tabular}{|l|l|l|}
\hline Interviewee & Job title consultancy & $\begin{array}{l}\text { Years in } \\
\text { career }\end{array}$ \\
\hline TC1 & $\begin{array}{l}\text { Technical } \\
\text { director }\end{array}$ \\
\hline TC2 & Documentation manager & $>10$ \\
\hline TC3 & Technical author & $>20$ \\
\hline TC4 & Technical writer & $<5$ \\
\hline
\end{tabular}

\section{How do practitioners characterize their professional contexts?}

While all of the interviewees were based within the software industry, they recognized that technical communication existed in different sectors of industry and that there were differences in requirements for roles between these sectors. TC1 highlighted the aerospace industry as an area which "still employ(s) conventional technical writers to do conventional technical writing" and where an engineering background was a requirement for technical writers. TC3 had worked as a writer in the software industry and was also involved in the recruitment of technical communicators. They made a clear distinction between the needs of software companies and hardware and engineering companies, identifying specifically aerospace, automotive, rail and nuclear as distinct sectors where their recruitment company did not have expertise. TC4 provided some examples of how different industry sectors had different requirements.

For example, in manufacturing, a lot of it's got to be printed, they're very heavily regulated. So you've got a lot of boilerplate text that has to be there. Whereas in the software industry, it's very fluid. [...] You can change things whenever you want.

TC4 also suggested that in their experience of searching for work, regional differences in the location of sectors meant that software-related jobs were primarily in the south east and jobs in manufacturing, further north.

TC1 indicated that their role involved gathering information for reports by interviewing people and then producing grammatically correct, readable reports. They also referred to user instruction as a key role for technical communicators, identifying the use of restricted language (in this case, ASTD) as a specific requirement for the aeronautical industry. TC4 also explicitly mentioned the information gathering aspects of their role as a major part of their work.

While all the respondents could identify with a 'technical communication industry', the boundaries were by no means clearly defined. For example, TC1 identified those working in content strategy as potentially part of this industry, though they came from professions in areas of "what used to be advertising and publicity and public relations". They also flagged up science writers, content strategists and information designers as others who potentially shared similar professional interests. TC2 had a similar view of the wide scope of roles coming under the umbrella of technical communication, giving the example of information architect and content strategist roles. For them, the issue was more about ensuring that individuals were aware their work was in the area of technical communication and they felt that some type of re-branding could help. They highlighted that the term 'technical communication' was often linked with the production of user manuals and stated that: "tech comm sounds dull. It sounds really dull, whereas, UX Writer sounds cooler..."

Different job titles may, however, mask different skillsets rather than reflecting merely cosmetic differences. For example, TC3 highlighted that in practice, distinctions tended to be made between user interface text and more traditional formats. They suggested that user research was an area of expertise that technical communicators needed to develop. A key question in relation to job titles is 
whether they reflect real differences in skills and competencies or whether they are different labels for the same work. TC3 also suggested the emergence of new areas of work blending different types of roles, "a hybrid between technical and copywriting".

\section{To what extent does the lack of educational programs in the UK impact on the profession?}

TC1 had an in-depth knowledge of technical communication programs in the UK and had been involved in the delivery of some of these in higher education. They described courses and programs driven by the enthusiasm of particular individuals, some more practical, and others more theoretical. For programs driven by one person's vision, once these individuals retired, the programs faded away. To a large extent, the programs were peripheral to the work of their academic departments, with few exceptions such as at the University of Reading. They also discussed courses provided by the ISTC in the past, as well as some commercial offerings.

TC3 provided some background on how technical communicators in the software industry were educated in the past through being placed on graduate schemes in companies such as Digital and IBM, gaining a few years of experience and then going on to work in the wider marketplace. This route was considerably diminished when many of these companies closed down, and in part with a shift of localization and documentation work to Ireland. Some individuals still take the graduate scheme training route (for example with IBM), but the numbers are smaller and individuals tend to stay longer with companies rather than migrating to other companies and sectors.

None of the interviewees had initially identified technical communication as a specific career destination. TC2 described "just fall(ing) into" their career path and reported that many other professionals had similar experiences. TC1 also recognized the lack of defined career paths into, and within, technical communication and felt that this posed a threat because "people won't understand what it is that we do and how we learn it and how we do it". They attributed at least part of this lack of recognition to a lack of education.

TC2 noted the importance of academic qualifications for the profession, suggesting that a Master's-level qualification in technical communication would have positive effects in giving the profession a higher profile. At the same time, however, they were reluctant to recommend mandatory qualifications for entry.

TC4 had received some instruction in technical communication on their undergraduate degree, that had provided a useful foundation for their work. They were aware of commercial course offerings and viewed them as interesting but they had not yet had an opportunity to take any. Their view was that courses focusing on technical aspects of technical communication such as learning to use new software, were not helpful as the technology changed very rapidly.

\section{To what extent are UK practitioners involved in professional communities?}

All of the interviewees were members of the ISTC and some had held leadership positions within the society. All recognized that membership in the society was falling but they viewed this decline in different ways. TC1 suggested that membership was falling because an aging membership meant that many left the society due to retirement rather than any dissatisfaction with its offerings. TC1 also referenced other professional organizations in the same field which were taking different approaches to retaining and building membership, such as the Society for Editors and Proofreaders (now the Chartered Institute for Editing and Proofreading).

TC2 blamed the diversity of emerging roles on the ISTC losing members: those in new roles do not see themselves as part of the technical communications community. This interviewee saw the challenge as enabling people to see themselves as "a tech comm professional ... regardless of what title you think you have or what kind of title you have".

For TC4, as the most recent entrant to technical communication, the society was a good way to orient themselves towards the industry. They joined the society at an early stage in their career and continued to be a member. For professional development, however, they saw it as peripheral. Instead much of their learning was through online resources, discussion boards. and online interaction with others who faced similar work challenges. TC2 referred to a growth in the number of non-members using the ISTC Facebook pages to interact with others, reflecting a shift towards online interaction that $\mathrm{TC} 1$ also observed. They discussed alternative informal communities, citing the Write the Docs initiative as impactful.

TC1 explained that the ISTC had a role in professional development, through education, as well as in helping members to develop networks for finding work. It provided training directly for a period, before moving toward a position of accrediting courses. In terms of finding work, TC1 gave an example of having a conversation about why technical writers in the engineering sector were not interested in joining the society and being told that this was "because they're within the [aeronautical] sector, there's always work for them". This suggests a focus on employment as a motivation for professional engagement, rather than learning new skills and standards in a developing field.

\section{CONCLUSION}

From this initial exploration of technical communication in the UK several themes have emerged. The first is the existence of potentially distinct 
communities of practice in different sectors, such as aerospace and nuclear. Industry practitioners in these areas may not be engaged with the ISTC as a professional body. Further work needs to be done in mapping communities of practice in different sectors which have traditionally employed technical communicators.

A related task would involve mapping boundaries between technical communication and areas previously regarded as separate. The data are too limited to demonstrate how job titles such as 'content manager' or 'information architect' fit into the framework of technical communication or whether they draw on other skillsets. The findings imply that new roles are emerging that blend skills requirements from technical communication with skills more traditionally associated with advertising or public relations. This is another area where more research is needed.

In the UK, professional roles and career paths for technical communicators are not clearly defined. There appears to be a lack of uniformity of routes to enter the profession, though this may depend on the sector. There are very few educational programs in the UK which are explicitly aimed at developing technical communication skills. While there is an awareness that these types of programs have potential to raise the professional profile of technical communication, there seems to be little appetite among those interviewed for mandatory professional level programs or courses. Commercially available courses seem to be well regarded, but not always of immediate interest.

Membership of the ISTC has declined, partly due to an ageing membership and partly due to declining numbers of more traditional technical communicators, resulting from a shrinking number of UK companies directly involved in technical activities, both in software and in manufacturing. Professional development and direct training provision by the society also seem to have declined, though it continues to accredit courses by other providers. In addition, there is evidence that alternative support structures are emerging online through informal training and collaboration groups.

\section{ACKNOWLEDGEMENTS}

We are very grateful to the interviewees whose generous, detailed and informative contributions form the basis of this study.

\section{REFERENCES}

[1] M. S. Larson, The Rise of Professionalism: A Sociological Analysis, Berkeley: University of California Press, 1977.

[2] K. MacDonald, The Sociology of the Professions, London, UK: Sage, 1995.

[3] Y. Cleary et al., "TecCOMFrame: A competence framework for technical communication," 2017 IEEE International
Professional Communication Conference (ProComm), 2017, pp. $1-5$.

[4] J. Kirkman, "From chore to profession: How technical communication in the United Kingdom has changed over the past twenty-five years," J. Tech. Writing Commun., vol. 26, no. 2, pp. 147-154, 1996.

[5] P. Hunt, "The teaching of technical communication in Europe: A report from Britain," Tech. Commun. Quart., vol. 2, no. 3, pp. 319-330, 1993.

[6] IT JobsWatch. [Online]. Available: https://www.itjobswatch.co.uk/

[7] C. Evia \& R. Andersen, "Preparing the next generation of leaders and innovators in technical communication," Intercom, vol. 65 , no. 4, 23-24, 2018.

[8] Prospects/HECSU, "Skills Shortages in the UK 2019/2020: An Insight into Occupational Shortages in the UK Labour Market," [Online]. Available: https://luminate.prospects.ac.uk/skills-shortages-in-the-uk

[9] E. H. Gorman, R. L. Sandefur, “'Golden age' quiescence and revival: How the sociology of professions became the study of knowledge-based work", Work Occupation, vol. 38, no. 3, pp. 275-302, 2011.

[10] Institute for Scientific and Technical Communication (ISTC). "Courses in technical communication." [Online]. Available: https://www.istc.org.uk/professional-developmentand-recognition/courses-in-technical-communication/\#academic

[11] E. Wenger, Communities of Practice: Learning Meaning and Identity, Cambridge, UK: Cambridge University Press, 1998.

\section{ABOUT THE AUTHORS}

Yvonne Cleary Yvonne Cleary is a lecturer in Technical Communication and Instructional Design at the University of Limerick, Ireland. Her research interests include professional issues in technical communication, technical communication pedagogy, virtual teams, and international technical communication. She has presented her work at conferences in Europe and the United States and has published in leading journals in the technical communication field.

Marie McCullagh is a Senior Lecturer in the School of Languages \& Applied Linguistics at the University of Portsmouth. She teaches technical and professional communication and applied linguistics at undergraduate and postgraduate level. Her research interests focus on spoken and written discourse in workplace contexts, with a particular interest in using authentic texts for instructional purposes. 